\title{
Características Anátomo-Estruturais da Pele de Ovinos (Ovis áries L.) Lanados e Deslanados, Relacionadas com o Aspecto Físico-Mecânico do Couro
}

\author{
Manuel Antonio Chagas Jacinto ${ }^{1}$, Américo Garcia da Silva Sobrinho², Roberto Germano Costa ${ }^{3}$
}

\begin{abstract}
RESUMO - O objetivo do estudo foi estabelecer as diferenças anátomo-estruturais da pele de ovinos deslanados da raça Morada Nova e ovinos lanados da raça Polwarth ou Ideal, relacionadas com as características físico-mecânicas dos couros. Foram utilizados dez animais de ambas as raças, com cinco animais de aproximadamente um e quatro anos de idade em cada raça. Os animais foram abatidos e, imediatamente após a esfola, foram retiradas amostras visando o estudo comparativo da pele nas regiões dorsal, lateral, ventral, anca e paleta. As peles dos ovinos Ideal apresentaram a camada termostática da derme maior que a camada reticular, com grande densidade folicular e glandular, ao contrário das peles dos ovinos Morada Nova, nas quais as referidas camadas tinham aproximadamente a mesma espessura, com menor densidade folicular e glandular. As peles foram depiladas, desengraxadas, curtidas ao cromo e recurtidas. Dos couros, nas regiões estudadas, foram retirados três corpos-de-prova nas direções paralela e perpendicular ao eixo céfalo-caudal, para os ensaios físico-mecânicos de resistência à tração, ao rasgamento e à distensão no lastômetro. A média dos resultados dos ensaios físico-mecânicos foram comparadas pelo teste de Tukey a 1 e $5 \%$ de probabilidade. A raça, a idade, a região e a posição exerceram efeito positivo nos valores de resistência do couro à tração, para os ovinos Morada Nova com quatro anos de idade, atingindo o mínimo de $200 \mathrm{~kg} / \mathrm{cm}^{2}$. A região e a posição exerceram efeito positivo nos valores de resistência do couro ao rasgamento para as duas raças de ovinos estudadas, atingindo o mínimo de $40 \mathrm{~kg} / \mathrm{cm}$. A resistência do couro à distensão, no ensaio de lastômetro, foi superior a $8 \mathrm{~mm}$, para todos os animais estudados, revelando elevada elasticidade dos couros, não sendo influenciada pela raça, idade, região ou posição.
\end{abstract}

Palavras-chave: couro, curtimento, ovino, pele, qualidade do couro

\section{Anatomical-Structural Characteristics of Wool-On and Non-Wool Sheep Skins Related to the Physical-Mechanic Leather Aspects}

\begin{abstract}
The objective of the study was establishing the anatomical-structural differences between the skin of non-wool sheep of the Morada Nova breed and wool-on sheep of the Polwarth or Ideal breeds and their relations to the physical-mechanical characteristics of their leather after tanning. Ten animals of both breeds were used, with five animals of approximately one and four years of age of each breed. The animals were slaughtered, and immediately after skinning, samples were taken viewing the microtomy of the skin in the dorsal, lateral, ventral, hind and palette regions, parallel and perpendicular to the head-tail axle, and perpendicular to the grain of the skin. The skins were depilated, chromium-tanned and re-tanned. From the leather, three samples were taken from the two directions considered from the regions studied for physical-mechanical analysis, for tension and tear resistance and distension on the lastometer. The average of the results of the physical-mechanical analysis were compared by Tukey test at the levels of 1 and 5\% probability. The breed, the age, the region and the position exerted a positive effect on the values of the resistance of the leather to tension for the Morada Nova four year old sheep, reaching a minimum of $200 \mathrm{~kg} / \mathrm{cm}^{2}$. The region and the position exerted a positive effect on the values of tear-resistence of the leather for both breeds studied, reaching a minimum of $40 \mathrm{~kg} / \mathrm{cm}$. The resistance of the leather on distension was superior to $8 \mathrm{~mm}$, for all the animals studied, not influenced by breed, age, region or position. The skin of the Ideal sheep presented a thermostatic skin layer greater than the reticular layer with great folicular and glandular density, contrary to the skin of the Morada Nova sheep where the thermostatic and reticular layers are of approximately the same thickness, with less folicular and glandular density.
\end{abstract}

Key Words: leather, leather quality, raw, skin, tanning

\section{Introdução}

Os ovinos possuem a pele revestida por folículos pilosos produtores de fibras de lã e/ou pêlo. No Brasil, as raças de ovinos caracterizadas pela presença de pêlos curtos na superfície corporal, denominadas deslanadas, são representadas pela Santa Inês (variedades vermelha, branca, preta e chitada), Morada Nova (variedades vermelha e branca), cujo nome está relacionado com sua região de origem no Estado

\footnotetext{
${ }^{1}$ Pesquisador do IPT - Instituto de Pesquisas Tecnológicas do Estado de São Paulo. S.A. CTCC - Centro Tecnológico de Couros e Calçados Franca, SP. E.mail: jacinto@francanet.com.br

2 Professor Adjunto do Departamento de Zootecnia - FCAV/UNESP - Jaboticabal, SP. E.mail: americo@fcav.unesp.br

3 Professor do Departamento de Agropecuária, do Centro de Formação de Tecnólogos, Campus IV da UFPB - CEP: 58.220-000 Bananeiras-PB. E.mail: rgermano@cft.ufpb.br
} 
do Ceará e Somalis (Silva Sobrinho, 1993). Os ovinos Morada Nova submetidos durante séculos a condições ambientais e nutricionais adversas, em processo de adaptação ao meio, por seleção natural (Domingues, 1941), tiveram a cobertura de lã gradualmente substituída por pêlos curtos, caminho inverso seguido pelos ovinos lanados durante a domesticação.

Alguns autores estudaram a morfologia da pele dos ovinos lanados e deslanados (Lyne \& Hollis, 1968; Kozlowski \& Calhoun, 1969; Pimenta, 1979), outros, as características físico-mecânicas dos couros (Boccone et al., 1978, 1980, 1983 e 1987), entretanto não analisaram simultaneamente a estrutura das peles e, após o curtimento, as propriedades dos couros, com o objetivo de estabelecer as diferenças intrínsecas, extrínsecas, intra e interespecíficas.

Considerando a importância econômica e social da raça Morada Nova na produção de carne e pele (Cavalcanti \& Silva, 1988; Mendonça Jr., 1995) e da Ideal na produção de carne e lã (Silva Sobrinho, 1993), este trabalho foi conduzido com o objetivo de analisar a relação existente entre as características estruturais da pele e a qualidade do couro, determinada por sua resistência mecânica, em diferentes idades, local e posição de amostragem na pele e no couro.

\section{Material e Métodos}

Foram utilizados ovinos deslanados da raça Morada Nova variedade vermelha e ovinos lanados da raça Polwarth ou Ideal, com padrões raciais definidos.

O grupo de estudo foi composto por 20 animais dez de cada raça, cinco com aproximadamente um ano de idade e cinco com cerca de quatro anos de idade, de ambos os sexos.

As amostras para os cortes histológicos foram retiradas com uma trefina (perfurador) de seção retangular (Carter \& Dowling, 1955; Nay, 1973), medindo $1,0 \mathrm{~cm}$ de comprimento por $0,5 \mathrm{~cm}$ de largura, das regiões dorsal, lateral, ventral, anca e paleta, sempre do lado direito da pele (Figura 1), imediatamente após o abate e esfola dos animais.

As amostras foram fixadas em Bouin por 48 horas e, em seguida, microtomizadas segundo técnica empregada por Pimenta (1979). Os cortes foram feitos na direção perpendicular ao plano da pele e, posteriormente, processados pela técnica de hematoxilina/eosina.

A análise da matriz extracelular foi feita observando-se os cortes histológicos em microscopia de polarização, utilizando como referência as características de birrefringência próprias dos feixes de fibras de colágeno (Junqueira et al., 1979; 1983a, 1983b; Vidal \& Mello, 1987).

A análise comparativa das glândulas sebáceas, sudoríparas, dos folículos pilosos, da camada termostática e reticular das peles, para as duas raças, foi feita por fotomicrografias (Jacinto, 1986) obtidas de um fotomicroscópio Karl Zeiss de polarização.

Após a retirada dos fragmentos para análise histológica, as peles dos ovinos recém esfolados foram conservadas em salga e secagem (Silva Sobrinho \& Jacinto, 1992). As peles foram curtidas ao cromo, seguindo as etapas de remolho, caleiro, desencalagem, purga, píquel, curtimento, basificação, neutralização, recurtimento, secagem e amaciamento, empregando metodologias (BASF, 1976; Bello et al., 1984), modificadas por Silva Sobrinho \& Jacinto (1992).

Os couros foram climatizados durante 48 horas sob temperatura de $20 \pm 2^{\circ} \mathrm{C}$ e umidade relativa de $65 \pm 2 \%$.

As medidas de espessura dos couros foram tomadas em equipamento e métodos estabelecidos pela norma ABNT (NBR 11052, 1997c) e destinaram-se aos cálculos de resistência à tração e ao rasgamento.

Os corpos-de-prova, para os ensaios de tração, rasgamento e lastômetro, foram retirados no balancim (prensa hidráulica), por meio de navalhas com dimensões determinadas pelas normas ABNT (NBR 11035, 1990; NBR 11669, 1991; NBR 11055, 1997a, NBR 11041, 1997b, NBR 11032, 1998).

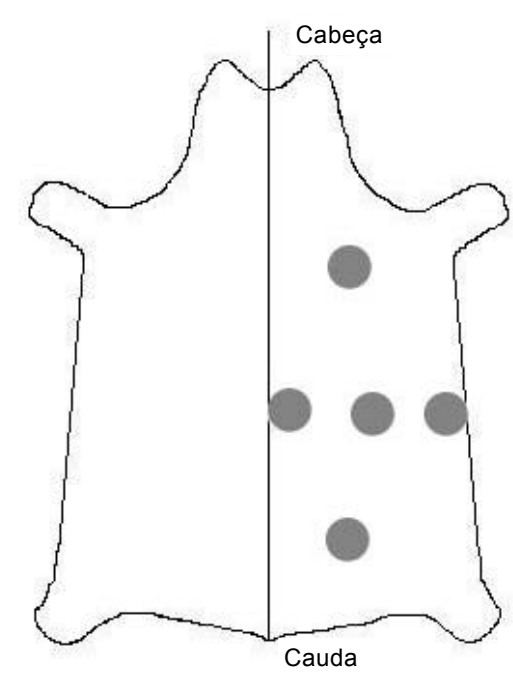

Figura 1 - Regiões de amostragem, vista da superfície dos pêlos ou lã.

Figure 1 - Sampling áreas, see of the hair or wool surface.

R. Bras. Zootec., v.33, n.4, p.1001-1008, 2004 
Nos ensaios de tração e rasgamento, foram utilizados três corpos-de-prova retirados dos couros nas regiões estudadas (Figura 1) na direção longitudinal, paralela ao eixo céfalo-caudal, e três corpos-deprova na direção transversal a este.

A medida da tensão de ruptura foi feita por um equipamento universal de ensaio (dinamômetro) marca IPT, com célula de carga de $200 \mathrm{~kg}$, calibrada com padrões rastreáveis.

A determinação de distensão e ruptura da superfície do couro pelo lastômetro foi realizada com três corpos-de-prova circulares, retirados das regiões do couro estudadas.

Nas duas raças de ovinos, com idades de 1 e 4 anos, foram avaliadas as partes do couro em duas direções. O delineamento experimental foi inteiramente casualizado em um sistema de parcelas sub-subdivididas, em que as parcelas foram representadas pelas duas raças e duas idades; as subparcelas, pelas cinco regiões do couro; e as sub-subparcelas, pelas duas posições (longitudinal e transversal), utilizando-se dez animais de cada raça.

\section{Resultados e Discussão}

Os resultados de resistência dos couros ovinos em estudo, considerando a raça, idade, região e posição, após serem submetidos à análise de variância, com as médias comparadas pelo teste Tukey, evidenciam que os ensaios de tração e rasgamento apresentaram diferenças significativas $(\mathrm{P}<0,01)$, indicando que o couro das duas raças possuem características distintas. Para o ensaio de lastômetro, considerando as mesmas fontes de variação, não foram observadas diferenças significativas $(\mathrm{P}>0,05)$.

Os couros das duas raças ultrapassaram, sem rompimento, $8,0 \mathrm{~mm}$ de distensão no ensaio de lastômetro, valor superior ao mínimo referência (Hoinacki, 1989) estabelecido para um couro de boa qualidade, caracterizando elevada elasticidade.

Os couros dos ovinos de quatro anos de idade, independentemente da raça, apresentaram valores médios de espessura e de resistência à tração maiores em relação aos mais jovens (Tabela 1). Comparando ovinos jovens e adultos, Pimenta (1979) encontrou diferença na distribuição e maior espessura das fibras colágenas e elásticas em ovinos adultos, ocorrência responsável pela influência na resistência à tração (Escudeiro, 1985). Em caprinos, o aumento da idade, em condições de nutrição ideais e sem a interferência de doenças, aumenta, proporcionalmente, o peso vivo, a área da superfície e a espessura da pele (Holst, 1990).

Os couros dos ovinos Morada Nova, nas duas idades, foram duas vezes mais resistentes à tração que os da raça Ideal. O valor mínimo esperado de resistência à tração é $200 \mathrm{~kg} / \mathrm{cm}^{2}$ (BASF, 1984), ultrapassado pelos couros dos ovinos Morada Nova de quatro anos de idade. $\mathrm{O}$ valor atingido pelos couros dos ovinos Morada Nova de um ano de idade se aproximou ao valor referência.

A superioridade do couro do ovino deslanado pode ser explicada por sua maior espessura e maior quantidade de fibras de colágeno distribuída nas

Tabela 1 - Valores médios dos ensaios de resistência à tração, em função da raça e da idade do animal e suas interações

Table 1 - Medium values of the tensile strength resistance tests, in function of animal breed and age and its interactions

\begin{tabular}{|c|c|c|c|c|c|}
\hline \multirow{2}{*}{$\begin{array}{l}\text { Variável } \\
\text { Variable }\end{array}$} & \multirow{2}{*}{$\begin{array}{l}\text { Raça } \\
\text { Breed }\end{array}$} & & \multicolumn{2}{|c|}{$\begin{array}{c}\text { Idade } \\
\text { Age }\end{array}$} & \multirow[t]{2}{*}{$\begin{array}{l}\mathrm{CV}^{1} \\
(\%)\end{array}$} \\
\hline & & & $\begin{array}{l}1 \text { ano } \\
1 \text { year }\end{array}$ & $\begin{array}{l}4 \text { anos } \\
4 \text { years }\end{array}$ & \\
\hline Espessura (mm) & $\begin{array}{l}\text { Morada Nova } \\
\text { Ideal }\end{array}$ & $\begin{array}{l}1,44^{\mathrm{a}} \\
1,09^{\mathrm{b}}\end{array}$ & $1,19^{\mathrm{A}}$ & $1,31^{\mathrm{A}}$ & 37,65 \\
\hline Carga de tração $(\mathrm{kg})$ & Morada Nova & $\begin{array}{r}28,30^{\mathrm{a}} \\
0,50 \mathrm{~b}\end{array}$ & $17,03^{\mathrm{A}}$ & $18,89^{\mathrm{A}}$ & 71,68 \\
\hline $\begin{array}{l}\text { Tensile load } \\
\text { Resistência à tracão }\left(\mathrm{kg} / \mathrm{cm}^{2}\right)\end{array}$ & $\begin{array}{l}\text { Ideal } \\
\text { Morada Nova }\end{array}$ & $\begin{array}{r}9,50^{b} \\
206,90^{a}\end{array}$ & $196.14^{\mathrm{Aa}}$ & $224.81^{\mathrm{Ba}}$ & /1,08 \\
\hline Tensile strenght & Ideal & $91,87^{b}$ & $83,24^{\mathrm{Ab}}$ & $100,50^{\mathrm{Bb}}$ & 42,91 \\
\hline
\end{tabular}

Médias seguidas da mesma letra, maiúscula na horizontal e minúscula na vertical, não diferem significativamente entre si $(P<0,05)$, pelo teste Tukey.

Means followed by the same letters, capital in the horizontal and small in the vertical, do not differ significantly $(P<.05)$ by Tukey test.

1 Coeficiente de variação de parcela (Parcel variation coefficient) 
camadas reticular e termostática (Figura 2A). A espessura da camada reticular da pele de animais produtores de lã é mais delgada (Figura 2B), comparada à dos ovinos produtores de pêlos (Pimenta, 1979; Chirita \& Probsdorfer, 1991).

Foi evidenciada, por intermédio da microscopia ótica de polarização, na pele do ovino lanado, a camada reticular, composta de feixes de fibras de colágeno birrefringentes (característica de certas estruturas quando submetidas à luz polarizada). $\mathrm{Na}$ camada termostática, por ser composta de pequena quantidade de colágeno, são visíveis somente as fibras de lã, por apresentarem birrefringência. Na pele do ovino deslanado, pela mesma técnica, foram observadas as camadas termostática e reticular esta composta de feixes de fibras de colágeno mais grossos que os observados na camada termostática.

Craig et al. (1987), estudando a organização ultraestrutural da pele de mamíferos, com especial atenção à sua função mecânica, notaram que as propriedades físicas estavam relacionadas com o diâmetro e comprimento das fibras de colágeno e sua distribuição na pele. A espessura e resistência da pele aumentam com o avanço da idade do animal e apresenta variações nas diferentes regiões (Pilotto \& Filosi, 1977). Peles de ovinos adultos, observadas pela microscopia eletrônica, apresentaram fibras colágenas de maior diâmetro quando comparados com animais jovens (Henrickson et al., 1984).

A organização dos folículos pilosos em ovinos consiste de um grupo básico de três folículos primários e um número variável de folículos secundários; os folículos primários precedem, na ontogenia, os folículos secundários. Todos os folículos primários, quando completamente diferenciados, estão associados a estruturas acessórias - glândula sudorípara, músculo eretor do pêlo e glândula sebácea. $\mathrm{O}$ folículo secundário está associado à glândula sebácea, que pode ser menor que a encontrada no folículo primário, ou totalmente ausente.

Jenkinson \& Nay (1975) e Noble (1984), estudando mamíferos, notaram que as glândulas sebáceas, sudoríparas, o músculo eretor do pêlo e o folículo piloso apareceram juntos, formando um arranjo convencionalmente denominado "unidade do folículo piloso". Na camada termostática da pele dos ovinos Ideal e Morada Nova, ocorre tal conjunto na proporção do número de folículos por unidade de área (Figuras $3 \mathrm{~A}$ e $3 \mathrm{~B})$.
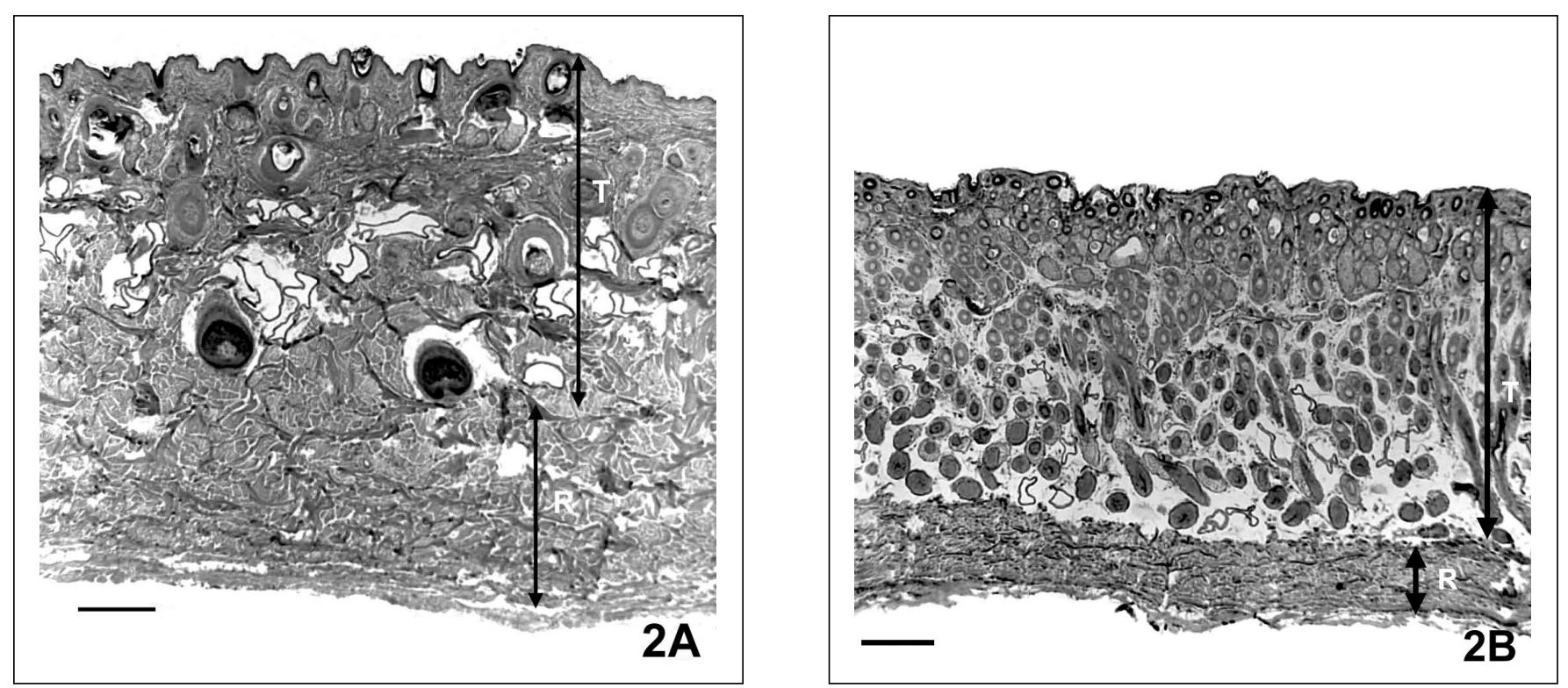

Figura 2 - (A) fotomicrografia da pele do ovino Morada Nova e (B) fotomicrografia da pele do ovino Ideal. Animais de 1 ano de idade, região da paleta, corte perpendicular ao plano da pele. A barra " $T$ " representa a camada termostática e a barra "R", a camada reticular (Barra horizontal - $225 \mu \mathrm{m}$ ).

Figure 2 - (A) photomicrography of the Morada Nova sheep skin and (B) photomicrography of the Ideal sheep skin. One year-old animals, area of the palette, cut perpendicular to the plan of the skin. The " $T$ " bar represents the thermostatic layer and the " $R$ " bar the reticular layer (Horizontal bar - $225 \mu \mathrm{m}$ ).

R. Bras. Zootec., v.33, n.4, p.1001-1008, 2004 
Nas etapas iniciais do processo de curtimento (caleiro e purga), são eliminados componentes não integrantes da rede de feixes de fibras de colágeno, por meio da ação de produtos alcalinos e enzimas. Tais produtos removem da camada termostática os pêlos ou as fibras de lã do interior do folículo e o lipídio das glândulas sebáceas, originando espaços vazios que, associados aos da porção secretora das glândulas sudoríparas, contribuem para o aumento dos espaços no interior dessa camada.

Decorrente da grande quantidade de folículos primários na pele do ovino Ideal e das estruturas associadas a eles (unidade do folículo piloso), o número de feixes de fibras formadores da rede de colágeno é reduzido, comparado ao dos Morada Nova, nos quais a quantidade de pêlo por unidade de área é menor.

Todas as variáveis foram influenciadas $(\mathrm{P}<0,01)$ quando analisadas nas diferentes regiões, com exceção da carga de tração $(\mathrm{P}>0,05)$, resultados coerentes com a metodologia estabelecida pela norma ABNT (NBR $11032,1998)$, que determina a retirada dos corpos-deprova em regiões pré-estabelecidas do couro.

A espessura da pele variou $(\mathrm{P}<0,05)$ em função da interação entre raça, idade e região, mostrando-se dependente principalmente da raça e da região. Os animais da raça Morada Nova apresentaram peles mais espessas e o comportamento da espessura nas regiões sofreu decréscimo no sentido dorso, lateral, ventre, com valores mais altos na paleta e anca.

$\mathrm{Na}$ interação entre raça e região (Tabela 2), a espessura média do couro dos ovinos Morada Nova, para os ensaios de tração e rasgamento, não variou $(\mathrm{P}>0,05)$ entre as regiões dorsal, lateral e ventral, e entre anca e paleta.

Os valores médios das cargas de tração e rasgamento dos couros dos ovinos Morada Nova foram superiores aos dos Ideal $(\mathrm{P}<0,05)$. As médias da carga de tração dos couros de Morada Nova diferiram entre si $(\mathrm{P}<0,05)$ nas diferentes regiões, com exceção das regiões dorsal e lateral. Para essa variável, os couros dos ovinos Ideal foram diferentes entre si $(\mathrm{P}<0,05)$, com exceção das regiões anca e paleta.

As médias da carga de rasgamento em cada raça diferiram entre si $(\mathrm{P}<0,05)$, com exceção das médias do ventre e paleta no ovino Ideal ( $\mathrm{P}>0,05)$, havendo decréscimo dos valores no sentido dorso, lateral e ventre, nas duas raças, voltando a aumentar na anca e paleta, acompanhando o comportamento da espessura.

A carga de tração, resistência à tração e resistência ao rasgamento foram influenciadas $(\mathrm{P}<0,05)$ pela posição (Tabela 3 ). Esses resultados são coerentes com a metodologia de retirada dos corpos-de-prova,
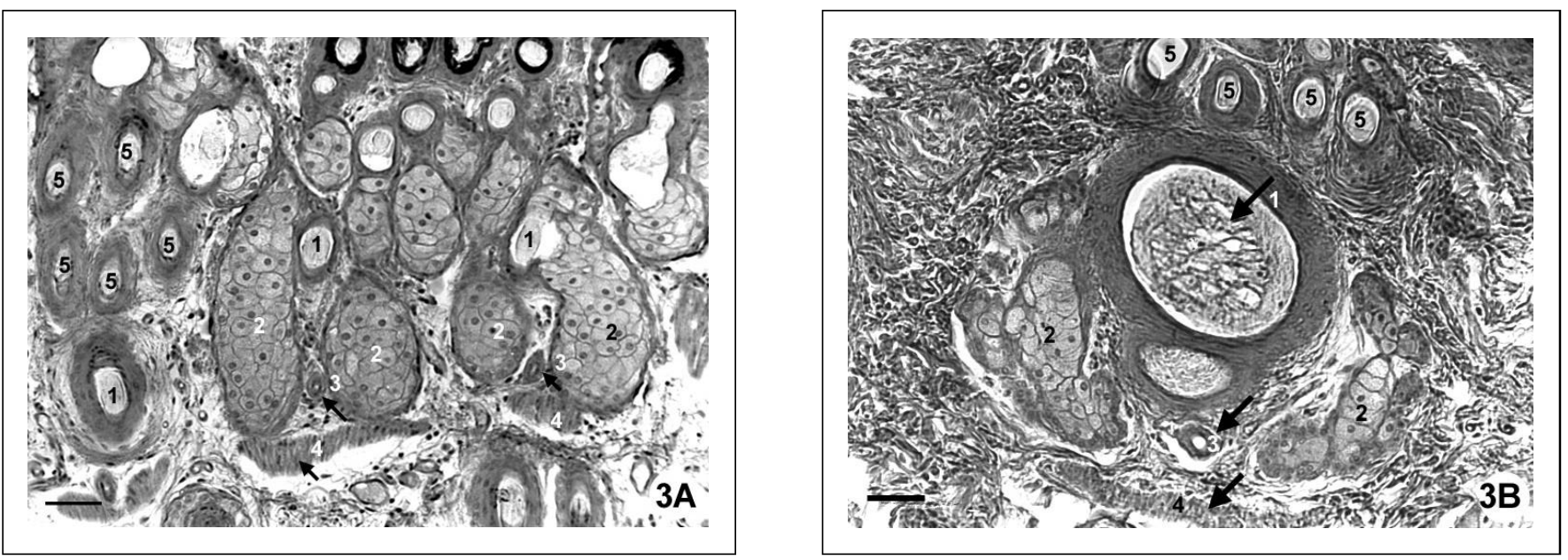

Figura 3 - (A) fotomicrografia da pele do ovino Ideal e (B) fotomicrografia da pele do ovino Morada Nova. Animais de 1 ano de idade, região da paleta. (1) folículo primário, (2) glândulas sebáceas, (3) duto da glândula sudorípara, (4) músculo eretor do pêlo, (5) folículo secundário. $(1+2+3+4)$ "unidade do folículo piloso" (Barra horizontal - $225 \mu \mathrm{m}$ ).

Figure 3 - (A) photomicrography of the Ideal sheep skin and (B) photomicrography of the Morada Nova sheep skin. One year-old animals, area of the palette. (1) primary follicle, (2) sebaceous glands, (3) duct of the sudoriferous gland, (4) erecting muscle of the hair, (5) secondary follicle. $(1+2+3+4)$ "unit of the hair follicle" (Horizontal bar - $225 \mu \mathrm{m})$.

R. Bras. Zootec., v.33, n.4, p.1001-1008, 2004 
determinada pelas normas ABNT (NBR 11055, 1997a; NBR11041, 1997b), na direção do eixo céfalo-caudal e perpendicular a ele, em regiões pré-determinadas do couro (Boccone et al., 1978; BASF, 1984).

A carga e resistência à tração foram maiores $(\mathrm{P}<0,05)$ na posição longitudinal, para as duas raças, entretanto, o inverso foi verificado para a resistência ao rasgamento, devido à orientação dos feixes de fibras de colágeno.

$\mathrm{Na}$ interação entre raça e posição (Tabela 3), somente a espessura, para o ensaio de rasgamento, apresentou diferenças entre as duas posições. Os animais Morada Nova apresentaram couros mais espessos $(\mathrm{P}<0,05)$ na posição longitudinal.

Entre as raças, nas duas posições, os couros dos ovinos Morada Nova apresentaram espessura superior à dos Ideal.

A carga de tração e a resistência à tração apresentaram diferenças $(\mathrm{P}<0,05)$ nas duas posições estudadas (Tabela 4); na interação entre região e posição, as médias da carga de tração foram sempre maiores para a posição longitudinal, com exceção da região da paleta, em que foi maior para a posição transversal.

Comportamento análogo tiveram as médias para o ensaio de resistência à tração, com maiores valores para a posição longitudinal. Tanto para a carga quanto para a resistência à tração, nas diferentes regiões e nas duas posições, as médias diferiram $(\mathrm{P}<0,05)$, com exceção das médias das cargas de tração das regiões dorsal e anca, que não diferiram na posição transversal.

A resistência dos couros ao rasgamento diferiu $(\mathrm{P}<0,05)$ nas duas posições, onde foi observado efeito contrário ao verificado para a resistência à tração (Tabela 4), na qual as médias da posição transversal foram maiores que as da posição longitudinal, com exceção da região ventral. Nas duas raças, as médias de resistência do couro ao rasgamento foram superiores ao mínimo de $40 \mathrm{kgf} / \mathrm{cm}$ exigido para um couro de boa qualidade. Esses resultados podem ter sido beneficiados pela ação do recurtente (Lubritan $\mathrm{WP}^{\circledR}$ ). As médias de todas as regiões nas duas posições apresentaram diferenças $(\mathrm{P}<0,05)$.

O comportamento dos couros nos ensaios de tração e rasgamento para as duas posições, uma perpendicular à outra, foi inverso, significando que a disposição dos feixes de fibras de colágeno exerceu influência em cada uma, confirmando a necessidade de novos ensaios com amostras nas duas posições.

Tabela 2 - Valores médios dos ensaios físico-mecânicos, em função da raça do animal e da região do couro, e suas interações

Table 2 - Mean values of the physical-mechanic assay, in function of the breed and leather region, and its interactions

\begin{tabular}{|c|c|c|c|c|c|c|c|}
\hline \multirow[t]{2}{*}{$\begin{array}{l}\text { Variável } \\
\text { Variable }\end{array}$} & \multirow[t]{2}{*}{$\begin{array}{l}\text { Raça } \\
\text { Breed }\end{array}$} & \multicolumn{5}{|c|}{$\begin{array}{l}\text { Região } \\
\text { Region }\end{array}$} & \multirow{2}{*}{$\begin{array}{l}\mathrm{CV}^{1} \\
(\%)\end{array}$} \\
\hline & & $\begin{array}{l}\text { Dorso } \\
\text { Dorsum }\end{array}$ & $\begin{array}{l}\text { Lateral } \\
\text { Lateral }\end{array}$ & $\begin{array}{l}\text { Ventre } \\
\text { Ventre }\end{array}$ & $\begin{array}{l}\text { Anca } \\
\text { Hind }\end{array}$ & $\begin{array}{l}\text { Paleta } \\
\text { Palette }\end{array}$ & \\
\hline Espessura (mm) & M. Nova & $1,37^{\mathrm{ABa}}$ & $1,35^{\mathrm{Aa}}$ & $1,39^{\mathrm{ABa}}$ & $1,59^{\mathrm{Ca}}$ & $1,50^{\mathrm{BCa}}$ & 10,56 \\
\hline Thickness & Ideal & $1,15^{\mathrm{Cb}}$ & $1,03^{\mathrm{ABb}}$ & $0,93^{\mathrm{Ab}}$ & $1,28^{\mathrm{Db}}$ & $1,05^{\mathrm{BCb}}$ & \\
\hline Carga de tração $(\mathrm{kg})$ & M. Nova & $28,90^{\mathrm{Ca}}$ & $28,81^{\mathrm{Ca}}$ & $26,78^{\mathrm{Ba}}$ & $26,50^{\mathrm{Aa}}$ & $30,52^{\mathrm{Da}}$ & 20,70 \\
\hline Tensile load & Ideal & $10,71^{\mathrm{Db}}$ & $10,05^{\mathrm{Cb}}$ & $8,45^{\mathrm{Ab}}$ & $9,15^{\mathrm{Bb}}$ & $9,13^{\mathrm{Bb}}$ & \\
\hline $\begin{array}{l}\text { Resistência à tração }\left(\mathrm{kg} / \mathrm{cm}^{2}\right) \\
\text { Tensile strenght }\end{array}$ & $\begin{array}{l}\text { M. Nova } \\
\text { Ideal }\end{array}$ & $155,23^{\mathrm{B}}$ & $154,83^{\mathrm{B}}$ & $140,52^{\mathrm{B}}$ & $119,31^{\mathrm{A}}$ & $145,08^{\mathrm{B}}$ & 17,81 \\
\hline Espessura (mm) & M. Nova & $1,35^{\mathrm{Aa}}$ & $1,35^{\mathrm{Aa}}$ & $1,33^{\mathrm{Aa}}$ & $1,52^{\mathrm{Ba}}$ & $1,50^{\mathrm{Ba}}$ & 11,66 \\
\hline Thickness & Ideal & $1,14^{\mathrm{Cb}}$ & $1,01^{\mathrm{ABb}}$ & $0,94^{\mathrm{Ab}}$ & $1,29^{\mathrm{Db}}$ & $1,06^{\mathrm{BCb}}$ & \\
\hline Carga de rasgamento $(\mathrm{kg})$ & M. Nova & $10,85^{\mathrm{Da}}$ & $10,56^{\mathrm{Ca}}$ & $9,08^{\mathrm{Aa}}$ & $9,60^{\mathrm{Ba}}$ & $11,56^{\mathrm{Ea}}$ & 14,99 \\
\hline Tear load & Ideal & $6,53^{\mathrm{Db}}$ & $5,33^{\mathrm{Bb}}$ & $4,90^{\mathrm{Ab}}$ & $5,51^{\mathrm{Cb}}$ & $4,93^{\mathrm{Ab}}$ & \\
\hline $\begin{array}{l}\text { Resistência ao rasgamento }(\mathrm{kg} / \mathrm{cm}) \\
\text { Tear strenght }\end{array}$ & $\begin{array}{l}\text { M. Nova } \\
\text { Ideal }\end{array}$ & $67,60^{\mathrm{C}}$ & $63,52^{\mathrm{BC}}$ & $58,80^{\mathrm{AB}}$ & $51,80^{\mathrm{A}}$ & $60,72^{\mathrm{BC}}$ & 17,76 \\
\hline
\end{tabular}

Médias seguidas da mesma letra, maiúscula na horizontal e minúscula na vertical, não diferem significativamente entre si $(P<0,05)$, pelo teste Tukey.

Means followed by the same letters, capital in the horizontal and small in the vertical, do not differ significantly ( $P<.05)$ by Tukey test.

1 Coeficiente de variação de parcela (Parcel variation coefficient). 
Tabela 3 - Valores médios dos ensaios físico-mecânicos, em função da raça do animal e da posição, e suas interações

Table 3 - Mean values of the physical-mechanic assay, in function of the breed and leather position, and its interactions

\begin{tabular}{|c|c|c|c|c|}
\hline \multirow[t]{2}{*}{$\begin{array}{l}\text { Variável } \\
\text { Variable }\end{array}$} & \multirow[t]{2}{*}{$\begin{array}{l}\text { Raça } \\
\text { Breed }\end{array}$} & \multicolumn{2}{|c|}{$\begin{array}{l}\text { Posição } \\
\text { Position }\end{array}$} & \multirow{2}{*}{$\begin{array}{l}\mathrm{CV}^{1} \\
(\%)\end{array}$} \\
\hline & & $\begin{array}{c}\text { Longitudinal } \\
\text { Longitudinal } \\
\end{array}$ & $\begin{array}{c}\text { Transversal } \\
\text { Traverse } \\
\end{array}$ & \\
\hline $\begin{array}{l}\text { Espessura (mm) } \\
\text { Thickness }\end{array}$ & $\begin{array}{l}\text { Morada Nova } \\
\text { Ideal }\end{array}$ & $1,22^{\mathrm{B}}$ & $1,27^{\mathrm{A}}$ & 9,72 \\
\hline $\begin{array}{l}\text { Carga de tração }(\mathrm{kg}) \\
\text { Tensile load }\end{array}$ & $\begin{array}{l}\text { Morada Nova } \\
\text { Ideal }\end{array}$ & $19,08^{\mathrm{A}}$ & $16,63^{\mathrm{B}}$ & 21,47 \\
\hline $\begin{array}{l}\text { Resistência à tração }\left(\mathrm{kg} / \mathrm{cm}^{2}\right) \\
\text { Tensile strenght }\end{array}$ & $\begin{array}{l}\text { Morada Nova } \\
\text { Ideal }\end{array}$ & $156,63^{\mathrm{A}}$ & $129,36^{\mathrm{B}}$ & 22,90 \\
\hline $\begin{array}{l}\text { Espessura }(\mathrm{mm}) \\
\text { Thickness }\end{array}$ & $\begin{array}{l}\text { Morada Nova } \\
\text { Ideal }\end{array}$ & $\begin{array}{l}1,44^{\mathrm{Aa}} \\
1,08^{\mathrm{Ab}}\end{array}$ & $\begin{array}{l}1,38^{\mathrm{Ba}} \\
1,10^{\mathrm{Ab}}\end{array}$ & 8,83 \\
\hline $\begin{array}{l}\text { Carga de rasgamento }(\mathrm{kg}) \\
\text { Tear load }\end{array}$ & $\begin{array}{l}\text { Morada Nova } \\
\text { Ideal }\end{array}$ & $7,48^{\mathrm{A}}$ & $7,75^{\mathrm{A}}$ & 13,14 \\
\hline $\begin{array}{l}\text { Resistência ao rasgamento }(\mathrm{kg} / \mathrm{cm}) \\
\text { Tear strenght }\end{array}$ & $\begin{array}{l}\text { Morada Nova } \\
\text { Ideal }\end{array}$ & $58,86^{\mathrm{B}}$ & $62,11^{\mathrm{A}}$ & 13,37 \\
\hline
\end{tabular}

Médias seguidas da mesma letra, maiúscula na horizontal e minúscula na vertical, não diferem significativamente entre si $(P<0,05)$, pelo teste Tukey.

Means followed by the same letters, capital in the horizontal and small in the vertical, do not differ significantly $(P<.05)$ by Tukey test.

1 Coeficiente de variação de parcela (Parcel variation coefficient).

Tabela 4 - Valores médios dos ensaios físico-mecânicos, em função da região do couro e da posição, e suas interações Table 4 - Medium values of the physical-mechanic assay, in function of the region and leather position, and its interactions

\begin{tabular}{|c|c|c|c|c|c|c|}
\hline \multirow[t]{2}{*}{$\begin{array}{l}\text { Variável } \\
\text { Variable }\end{array}$} & \multirow[t]{2}{*}{$\begin{array}{l}\text { Posição } \\
\text { Position }\end{array}$} & \multicolumn{5}{|c|}{$\begin{array}{l}\text { Região } \\
\text { Region }\end{array}$} \\
\hline & & $\begin{array}{c}\text { Dorso } \\
\text { Dorsum }\end{array}$ & $\begin{array}{l}\text { Lateral } \\
\text { Lateral }\end{array}$ & $\begin{array}{l}\text { Ventre } \\
\text { Ventre }\end{array}$ & $\begin{array}{l}\text { Anca } \\
\text { Hind }\end{array}$ & $\begin{array}{l}\text { Paleta } \\
\text { Palette }\end{array}$ \\
\hline $\begin{array}{l}\text { Espessura (mm) } \\
\text { Thickness }\end{array}$ & $\begin{array}{l}\text { Longitudinal } \\
\text { Longitudinal } \\
\text { Transversal } \\
\text { Traverse }\end{array}$ & $1,25^{\mathrm{B}}$ & $1,18^{\mathrm{BC}}$ & $1,14^{\mathrm{C}}$ & $1,42^{\mathrm{A}}$ & $1,25^{\mathrm{B}}$ \\
\hline Carga de tracão $(\mathrm{kg})$ & $\begin{array}{l}\text { Longitudinal } \\
\text { Longitudinal }\end{array}$ & $21,41^{\mathrm{Aa}}$ & $19,61^{\mathrm{Ba}}$ & $18,74^{\mathrm{Ca}}$ & $17,52^{\mathrm{Da}}$ & $18,13^{\mathrm{Ea}}$ \\
\hline Tensile load & $\begin{array}{l}\text { Transversal } \\
\text { Traverse }\end{array}$ & $16,18^{\mathrm{Ab}}$ & $17,16^{\mathrm{Bb}}$ & $14,44^{\mathrm{Cb}}$ & $16,20^{\mathrm{Ab}}$ & $19,15^{\mathrm{Db}}$ \\
\hline Resistência à tração $\left(\mathrm{kg} / \mathrm{cm}^{2}\right)$ & $\begin{array}{l}\text { Longitudinal } \\
\text { Longitudinal }\end{array}$ & $182,11^{\mathrm{Aa}}$ & $169,81^{\mathrm{Ba}}$ & $157,42^{\mathrm{Ca}}$ & $127,85^{\mathrm{Da}}$ & $45,96^{\mathrm{Ea}}$ \\
\hline Tensile strenght & $\begin{array}{l}\text { Transversal } \\
\text { Traverse } \\
\text { Longitudinal }\end{array}$ & $128,34^{\mathrm{Ab}}$ & $139,86^{\mathrm{Bb}}$ & $123,61^{\mathrm{Cb}}$ & $110,77^{\mathrm{Db}}$ & $44,20^{\mathrm{Eb}}$ \\
\hline $\begin{array}{l}\text { Espessura (mm) } \\
\text { Thickness }\end{array}$ & $\begin{array}{l}\text { Longitudinal } \\
\text { Transversal } \\
\text { Traverse }\end{array}$ & $1,24^{\mathrm{B}}$ & $1,16^{\mathrm{BC}}$ & $1,11^{\mathrm{C}}$ & $1,39^{\mathrm{A}}$ & $1,26^{\mathrm{B}}$ \\
\hline $\begin{array}{l}\text { Carga de rasgamento }(\mathrm{kg}) \\
\text { Tear load }\end{array}$ & $\begin{array}{l}\text { Longitudinal } \\
\text { Longitudinal } \\
\text { Transversal } \\
\text { Traverse }\end{array}$ & $8,45^{\mathrm{A}}$ & $7,66^{\mathrm{B}}$ & $6,76^{\mathrm{C}}$ & $7,33^{\mathrm{BC}}$ & $7,88^{\mathrm{AB}}$ \\
\hline Resistência ao rasgamento $(\mathrm{kg} / \mathrm{cm})$ & $\begin{array}{l}\text { Longitudinal } \\
\text { Longitudinal }\end{array}$ & $62,71^{\mathrm{Aa}}$ & $61,36^{\mathrm{Ba}}$ & $59,76^{\mathrm{Ca}}$ & $51,34^{\mathrm{Da}}$ & $59,12^{\mathrm{Ea}}$ \\
\hline Tear strenght & $\begin{array}{l}\text { Transversal } \\
\text { Traverse }\end{array}$ & $72,49^{\mathrm{Ab}}$ & $65,68^{\mathrm{Bb}}$ & $57,83^{\mathrm{Cb}}$ & $52,25^{\mathrm{Db}}$ & $62,32^{\mathrm{Eb}}$ \\
\hline
\end{tabular}

Médias seguidas da mesma letra, maiúscula na horizontal e minúscula na vertical, não diferem significativamente entre si $(P<0,05)$, pelo teste Tukey.

Means followed by the same letters, capital in the horizontal and small in the vertical, do not differ significantly (P<.05) by Tukey test.

R. Bras. Zootec., v.33, n.4, p.1001-1008, 2004 


\section{Conclusões}

A resistência dos couros ovinos à tração e ao rasgamento é influenciada pelas características anátomo-estruturais da pele, pela raça (Morada Nova e Ideal), idade, região e posição de retirada das amostras.

\section{Literatura Citada}

ASSOCIAÇÃO BRASILEIRA DE NORMAS TÉCNICAS ABNT. Corte de corpos-de-prova em couro, NBR11035, Rio de Janeiro, 1990. 1p.

Couros: determinação da ruptura e da distensão da flor - Lastômetro, NBR 11669. Rio de Janeiro, 1991. $4 \mathrm{p}$.

Couros: determinação da força de rasgamento progressivo, NBR11055. Rio de Janeiro, 1997a. 4p.

Couros: determinação da resistência à tração e alongamento, NBR11041. Rio de Janeiro, 1997b. 3p. Couros: determinação da medida de espessura, NBR11052. Rio de Janeiro, 1997c. 3p.

Tomada de provas em peles e couros, NBR11032. Rio de Janeiro, 1998. 5p.

BASF. Pieles de animales pequeños: curtición, recurtición, tintura, engrase y acabado. Ludwigshafen, 1976. 41p.

BELLO, M.; BOCCONE, R.I.; FONTANA, J. Optimización del proceso de curtido de cueros ovinos con lana. Monografia Tecnologica, n.16, p.1-8, 1984.

BOCCONE, R.I.; FONTANA, J.A.; KAMP, G. Distribution of mechanical properties in wool-on sheepskins. Journal Society Leather Trades Chemists, v.62, p.128-32, 1978.

BOCCONE, R.I.; FONTANA, J.; BELLO, M. El desengrase de cueros ovinos. Monografia Tecnologica, n.7, p.1-11, 1980. Influencia de los productos de recurtido sobre las propiedades mecánicas de cueros ovinos con lana. Monografia Tecnologica, n.15, p.1-14, 1983.

Influencia de algunos agentes de engrase sobre las propiedades de cueros ovinos sin lanas. Monografia Tecnologica, n.18, p.1-12, 1987.

CARTER, H.B.; DOWLING, D.F. The hair follicle and apocrine gland population of cattle skin. Australian Journal Agricultural Research, v.5, n.4, p.745-757, 1955.

CAVAlCANTI, G.; SILVA, R.C. Aspectos da caprinoovinocultura na região nordeste: tecnologia, produção e comercialização. Recife: SUDENE/DPS/ AAB, 1988. 36p.

CRAIG, A.S.; EIKENBERRY, E.F.; PARRY, D.A.D. Ultrastructural organization of skin: classification on the basis of mechanical role. Connective Tissue Research, v.16, p.213-23, 1987.

DOMINGUES, O. Carneiro deslanado de Morada Nova. Boletim Sociedade Brasileira Agronomia, v.41, n.1, p.122, 1941.

ESCUDERO, L.R. Estudio de la piel. In:ADZET ADJET, J. M.; SOLE, J.S.; BONET, J.B. (Eds.) Quimica tecnica de teneria. Barcelona: Romanyà/Valls, 1985. 765p.
HENRICKSON, R.L.; RANGANAYAKI, M.D.; ASGHAR, A. Age, species, breed, sex, and nutrition effect on hide collagen. Critical Reviews in Food Science Nutrition, v.20, n.3, p.159-72, 1984 .

HOINACKI, E. Peles e couros. 2.ed. Porto Alegre: CFP de Artes Gráficas, 1989. 320p.

HOLST, P.J. Pretanning factors that affect the grain appearance on goat leather. Cowra: NSW Agriculture \& Fisheries, 1990. p.1-5. (Technical Bulletin, 36)

JACINTO, M.A.C. Fotomicrografia. Ribeirão Preto: Faculdade de Medicina, 1986. 26p. (Monografia).

JENKINSON, D.M.E.; NAY, T. The sweat glands and hair follicles differents species of Bovidae. Australian Journal Biological Science, v.28, p.55-68, 1975.

JUNQUEIRA, L.C.U.; BIGNOLAS, G.; BRENTANI, R.R. Picrosirius staining plus polarization microscopy, a specific method for collagen detection in tissue sections. Histochemical Journal, v.11, p.447-55, 1979.

JUNQUEIRA, L.C.U.; JOAZEIRO, P.P.; MONTES, G.S. et al. The collagen fiber architecture of Brazilian naked catfish skin. Brazilian Journal Medicine Biological Research, v.16, p.313-16, 1983a.

Dermal collagen distribution, a histochemical and ultrastructural study. Histochemistry, v.79, p.397-403, 1983b.

LYNE, A.G.; HOLLIS, D.E. The skin of the sheep: a comparison of body regions. Australian Journal Biological Science, v.21, p.499-527, 1968.

KOZLOWSKI, G.P.; CALHOUN, M.L. Microscopic anatomy of the integument of sheep. American Journal Veterinary Research, v.30, n.8, p.1267-79, 1969.

MENDONÇA JR., R. Pele de carneiro serve para fazer sapato fino. O Estado de São Paulo. São Paulo, 6 dez. 1995. Suplemento Agrícola, p.G9.

NAY, T. Technique for examining wool follicles in the skin of sheep. Melbourne: Australian Wool Corporation, 1973. 15p.

NOBLE, R.C.; FINDLAY, J.D.; YANG, S.H. et al. Lipid compositions of the bovine epidermis. Research Veterinary Science, v.37, p.120-22, 1984.

PILOTTO, F.; FILOSI, M. Relationship between collagen fibril diameters and body size. Cellular Tissue Research, s.l, v.182, p.119-31, 1977.

PIMENTA, J.T.S. Estudo histológico da pele de ovinos (Ovis aries) criados no nordeste brasileiro. Rio de Janeiro: Universidade Federal do Rio de Janeiro, 1979. 76p. Dissertação (Mestrado em Histologia) - Universidade Federal do Rio de Janeiro, 1979.

SILVA SOBRINHO, A.G.; JACINTO, M.A.C. Peles ovinas. 1.ed. Jaboticabal: FUNEP, 1992. 33p.

Tópicos em ovinocultura. Jaboticabal: Universidade Estadual Paulista, 1993. 179p. (Apostila).

VIDAL, B.C.; MELLO, M.L.S. Biologia celular. São Paulo: Atheneu, 1987. 347p. 